\title{
Potentiometric Studies on the Equilibria of Flufenamic Acid in Aqueous Solutions and in Two-phase Organic Solvent + Water Systems
}

\author{
Lidia Zapała
}

Received: 17 March 2010 / Accepted: 12 July 2010 / Published online: 12 January 2011

(C) The Author(s) 2011. This article is published with open access at Springerlink.com

\begin{abstract}
In this paper, the flufenamic acid equilibria in aqueous solution and in two-phase organic solvent + aqueous solution are described and presented. The dissociation constants $K_{\mathrm{a} 1}$ and $K_{\mathrm{a} 2}$ were determined in MDM + water mixtures. The Yashuda-Shedlovsky extrapolation procedure has been used to obtain the values of $K_{\mathrm{a} 1}$ and $K_{\mathrm{a} 2}$ in aqueous solutions. The distribution ratio $D$ was measured in the toluene + water system over a wide range of $\mathrm{pH}$ by the shaking flask method. Based on the results of potentiometric titrations in two-phase organic solvent (benzene, ethylbenzene, toluene, carbon tetrachloride, chloroform, chlorobenzene, and bromobenzene) + aqueous systems, and using models of single and multistep equilibria, the values of distribution constants $K_{\mathrm{D}}$ and dimerization constants $K_{\text {dim }}$ were calculated. The influences of polarity of the applied solvents and $\mathrm{pH}$ of the aqueous phase, on the speciation of the particular forms of flufenamic acid in both phases, were demonstrated.
\end{abstract}

Keywords Flufenamic acid · Dissociation constant $\cdot$ Two-phase equilibria · Distribution constant

\section{Introduction}

Flufenamic acid ( $N$-(3-trifluoromethylphenyl)anthranilic acid) belongs to a group of nonsteroidal anti-inflammatory drugs with the diphenylamine structure. It has analgesic and antipyretic properties and is used in the treatment of musculoskeletal and joint disorders such as osteoarthritis, rheumatoid arthritis and post trauma inflammation [1-3]. It is an inhibitor of inorganic anion transport (and is an especially potent inhibitors of sulfate transport) in erythrocytes [4]. It is known to occur in at least six polymorphic forms [2]. Despite of the use of many analytical methods for detection and identification of flufenamic acid (HPLC, GC-MS, UV-VIS spectrophotometry, spectrofluorimetry, voltammetry) [5-8], its physicochemical properties in solutions, especially in two-phase systems, have been insufficiently

\footnotetext{
L. Zapała $(\bowtie)$

Department of Inorganic and Analytical Chemistry, Faculty of Chemistry, Rzeszów University of Technology, 6 Powstańców Warszawy Ave., 35-959 Rzeszów, Poland e-mail: 1zapala@prz.edu.pl 
studied. Data on the distribution of this acid in systems with organic solvents are incomplete and mainly concerned with the octanol system [9-11]. These limited data do not allow one to predict the physicochemical properties and behavior of the studied acid in systems with other organic solvents.

The ionization constant is an important physicochemical parameter of a substance, and knowledge of this parameter is of fundamental importance for a wide range of applications and research areas. Moreover, knowledge of this constant is needed to determine the distribution constants using the potentiometric method. There are several methods for the determination of dissociation constants, but potentiometry is still one of the most commonly used methods because of its accuracy and reproducibility [12, 13]. Furthermore, analysis of the titration data is easily achieved with the help of spreadsheets via curve fitting of the titration curve or of the difference curve. The use of computer programs for the refinement of equilibrium constants allows the determination of the different $\mathrm{p} K_{\mathrm{a}}$ values for polyprotic substances, even when they are numerically very close [14-16]. However, when the tested compound has poor solubility, this method presents difficulties and the obtained results are not reliable. In this case, alternative methods such as the mixed-solvent procedure can be used. This method is based on the measurement of apparent dissociation constants in mixtures with different ratios of organic solvent (methanol [17-22], ethanol, dimethylsulfoxide, dimethylformamide, dioxane [18], propanol [20], acetone [18, 20] izopropyl alkohol [23]) to water. The aqueous dissociation constant is obtained by extrapolation (for example using the Yashuda-Shedlovsky procedure) to pure water as solvent.

The reported literature data indicate that methanol shows a solvation effect close to water and this solvent has the widest application in this type of research [17, 20-22]. However, from results of experimental studies, not all compounds dissolve in any single organic solvent + water mixtures. In connection with this problem, multicomponent co-solvent mixtures, consisting of equal volumes of methanol $(\mathrm{MeOH})$, dioxane and acetonitrile $(\mathrm{MeCN})$, were prepared. This mixture, termed MDM, improves the solubility of the hydrophobic compounds, is a good solvent for polar molecules, and fulfills all the requirements that are needed for the application of the $\mathrm{pH}$-metric method. The validation of $\mathrm{p} K_{\mathrm{a}}$ values determined in MDM + water mixtures was presented in [24].

In this work the acid-base properties (in terms of the dissociation constants $K_{\mathrm{a} 1}, K_{\mathrm{a} 2}$ and isoelectric point $\mathrm{pH}_{\mathrm{i}}$ ) of flufenamic acid were studied by potentiometry. The partitioning profile of flufenamic acid was obtained by the shaking flask method in the toluene + water solvent system. Based on the results of potentiometric titrations in two-phase systems of organic solvent (benzene, ethylbenzene, toluene, carbon tetrachloride, chloroform, chlorobenzene, or bromobenzene) + water solutions, and using models of single and multistep equilibria, values of the distribution constants $K_{\mathrm{D}}$ and dimerization constants $K_{\text {dim }}$ were calculated. Moreover, the influence of the selected parameters $(\mathrm{pH}$ of the aqueous phase, structure and polarity of the organic solvent) on the equilibria were analyzed with regard of the formation and coexistence of different forms of this acid in the examined systems.

\section{Experimental Section}

\subsection{Materials}

Flufenamic acid was purchased from the Sigma Chemical Co. The organic solvents (benzene, toluene, ethylbenzene, chlorobenzene, bromobenzene, nitrobenzene and methanol, 1,4-dioxane, acetonitrile) were purchased from Fluka and POCh (Poland) and were used without further purification. Potassium chloride, potassium hydroxide, and hydrochloric acid were also purchased from POCh. All reagents were of analytical grade. 


\subsection{Potentiometric Apparatus}

The free hydrogen-ion concentration was measured via electromotive force by means of a CPI-505 pH-meter (Elmetron) $(\mathrm{E} \pm 0.2 \mathrm{mV})$ with an $\mathrm{OSH} 10-00$ combined electrode (Metron). All titrations were performed in a thermostatted double-walled glass vessel of $100 \mathrm{~cm}^{3}$ at the temperature $25.0 \pm 0.1^{\circ} \mathrm{C}$ under nitrogen atmosphere. The burette was calibrated by weighing doubly distilled and purified water, with a precision of $\pm 0.02 \%$ in added volume over the whole volume range.

\subsection{Potentiometric $\mathrm{p} K_{\mathrm{a}}$ Determinations}

For the calibration of the glass electrode in MDM + water mixtures, $\mathrm{HCl}$ solutions of known concentrations containing 35.0-60.0\% (v/v) of MDM were titrated with a KOH solution. These potassium hydroxide and hydrochloric acid solutions were each prepared in the MDM + water solvent systems by suitable dilution of a $1.000 \mathrm{~mol} \cdot \mathrm{dm}^{-3}$ standardized solution [25]. Titrations were conducted in the $\mathrm{pH}$ range 2.0-12.0 at a constant ionic strength $\left(I=0.15 \mathrm{~mol} \cdot \mathrm{dm}^{-3}, \mathrm{KCl}\right)$ and temperature $\left(25.0 \pm 0.1^{\circ} \mathrm{C}\right)$. The Nernst equation parameters for the glass electrode for each of these solvent mixtures were evaluated using a set of experimental data (Emf versus titrant volume). Calibration of the electrodes in each system was performed at least twice. The changes in $p_{\mathrm{s}} K_{\mathrm{w}}$ values versus mass fraction of MDM were evaluated on the basis of the polynomial equation reported in [26]. The obtained values are presented in Table 1 .

Potentiometric titrations of flufenamic acid were carried out under the same conditions as the electrode calibrations. Six separate semi-aqueous solutions containing 35.0-60.0\% (v/v) of MDM, $0.001 \mathrm{~mol} \cdot \mathrm{dm}^{-3}$ flufenamic acid, and $0.15 \mathrm{~mol} \cdot \mathrm{dm}^{-3} \mathrm{KCl}$ (to adjust ionic strength, which not only mimicks the ionic strength of blood but greatly simplified the correction of the $\mathrm{pH}$ for its ionic strength dependence) were prepared. The solutions were first acidified with the $\mathrm{HCl}$ solution and then titrated with the appropriate $\mathrm{KOH}$ solution (prepared in each MDM + water solvent mixture by suitable dilution of $1.000 \mathrm{~mol} \cdot \mathrm{dm}^{-3}$ standardized solution [25]) to $\mathrm{pH} \sim 11$. Titrations of each system were repeated in triplicate. Activity coefficient corrections for the measured $\mathrm{pH}$ were made on the basis of Eq. 1 [27, 28]:

$$
\mathrm{pH}=\mathrm{pH}_{\text {meas }}+\log _{10} \gamma_{i}
$$

where $\gamma_{i}$ is the activity coefficient.

Table 1 Values of the parameters characterizing the MDM + water mixtures, and $\mathrm{p}_{\mathrm{s}} K_{\mathrm{a} 1}$ and $\mathrm{p}_{\mathrm{s}} K_{\mathrm{a} 2}$ for flufenamic acid in these MDM + water systems

Values obtained by the Yasuda-Shedlovsky procedure

\begin{tabular}{llllll}
\hline $\mathrm{wt} \% \mathrm{MDM}$ & $A$ & $a_{0} B$ & $\mathrm{p}_{\mathrm{s}} K_{\mathrm{w}}$ & $\mathrm{p}_{\mathrm{s}} K_{\mathrm{a} 1}$ & $\mathrm{ps}_{\mathrm{a} 2}$ \\
\hline 56.48 & 1.024 & 1.840 & 15.256 & $3.08 \pm 0.02$ & $6.60 \pm 0.03$ \\
51.39 & 0.944 & 1.795 & 15.147 & $3.06 \pm 0.01$ & $6.32 \pm 0.03$ \\
46.38 & 0.874 & 1.753 & 15.014 & $3.05 \pm 0.01$ & $6.13 \pm 0.03$ \\
41.45 & 0.813 & 1.716 & 14.867 & $3.04 \pm 0.02$ & $5.96 \pm 0.04$ \\
36.57 & 0.760 & 1.682 & 14.713 & $3.02 \pm 0.01$ & $5.76 \pm 0.03$ \\
31.77 & 0.711 & 1.648 & 14.559 & $3.00 \pm 0.02$ & $5.58 \pm 0.02$ \\
0.00 & & & & $2.92^{\mathrm{a}} \pm 0.01$ & $4.84^{\mathrm{a}} \pm 0.04$ \\
& & & & $\left(r^{2}=0.9972\right)$ & $\left(r^{2}=0.9969\right)$ \\
\hline
\end{tabular}


The activity coefficients in MDM + water mixtures were calculated by using the DebyeHückel equation (Eq. 2):

$$
\log _{10} \gamma_{i}=-\frac{A z^{2} \sqrt{I}}{1+a_{0} B \sqrt{I}}
$$

where $I$ is the ionic strength $\left(I=0.5 \sum\left(c_{i} z_{i}^{2}\right)\right), A$ and $B$ are the Debye-Hückel constants, and $a_{0}$ is a parameter dependent on the ion size, which is assigned a value fixed by the Bates-Guggenheim convention [29] extended to solvents of moderate relative permittivities.

Values of the Debye-Hückel constants $A$ for each investigated solution have been calculated separately using Eq. 3 [30]:

$$
A=\frac{F^{3}}{4 \pi N_{A} \ln 10}\left(\frac{\rho}{2 \varepsilon^{3} R^{3} T^{3}}\right)^{1 / 2}
$$

where $F$ is the Faraday constant, $N_{\mathrm{A}}$ the Avogadro constant, $R$ the gas constant, $T$ the temperature, and $\varepsilon$ and $\rho$ are the dielectric constant and density of the MDM + water mixture, respectively.

Values of $a_{0} B$ were calculated based on Eq. 4 [25]:

$$
a_{0} B=1.5 \sqrt{\frac{\varepsilon_{\mathrm{w}} \rho}{\varepsilon \rho_{\mathrm{w}}}}
$$

where $\varepsilon_{\mathrm{w}}$ and $\rho_{\mathrm{w}}$ denote the dielectric constant and density of water, respectively.

\subsection{Shaking Flask Determination of the Distribution Ratio $D$}

Investigations on the distribution of flufenamic acid were performed in the $\mathrm{pH}$ interval 112 at $25 \pm 0.1{ }^{\circ} \mathrm{C}$. Organic and aqueous phases were mutually saturated. Britton-Robinson buffers (acetic, phosphoric and boric acids, each at $0.04 \mathrm{~mol} \cdot \mathrm{dm}^{-3}$, and treated with various amounts of $0.2 \mathrm{~mol} \cdot \mathrm{dm}^{-3} \mathrm{NaOH}$ ) were used as the aqueous phase for the $\mathrm{pH}$ range 2.0 to 12.0. To obtain $\mathrm{pH}=1,0.1 \mathrm{~mol} \cdot \mathrm{dm}^{-3}$ hydrochloric acid was used. The tested compound was dissolved in toluene. A sample $\left(5.0 \mathrm{~cm}^{3}\right)$ of the organic solvent containing flufenamic acid $\left(1 \times 10^{-4} \mathrm{~mol} \cdot \mathrm{dm}^{-3}\right)$ and an equal volume of the aqueous phase were agitated vigorously in a stoppered glass tube for $1 \mathrm{~h}$ to reach the equilibrium, and then allowed to set for $2 \mathrm{~h}$ in order to yield phase separation. A preliminary study showed that this time was sufficient to reach the partitioning equilibrium. The $\mathrm{pH}$ of the aqueous phase was subsequently measured. The UV absorbances of flufenamic acid in the organic phase at equilibrium were measured with a Beckman DU-640 spectrophotometer at $\lambda_{\max }=353 \mathrm{~nm}$. The concentration of the amino acid in the aqueous phase was calculated on the basis of mass balance of the amino acid in the two-phase system.

\subsection{Determination of the Distribution Constant $K_{\mathrm{D}}$ and Dimerization Constant $K_{\mathrm{dim}}$ Values}

The potentiometric titrations of flufenamic acid in the two-phase systems organic solvent + aqueous solution $\left(\mathrm{KCl}, I=0.15 \mathrm{~mol} \cdot \mathrm{dm}^{-3}\right)$ were conducted using benzene, ethylbenzene, toluene, chlorobenzene, and bromobenzene as the organic phase. Solutions of flufenamic acid were prepared at $0.01 \mathrm{~mol} \cdot \mathrm{dm}^{-3}$ in the investigated organic solvents saturated with aqueous phase $\left(30 \mathrm{~cm}^{3}\right)$. The aqueous phase $\left(\mathrm{KCl}, I=0.15 \mathrm{~mol} \cdot \mathrm{dm}^{-3}\right)$ was initially acidified to $\mathrm{pH}$ about 2 with standardized $0.1 \mathrm{~mol} \cdot \mathrm{dm}^{-3} \mathrm{HCl}$. Titration was then carried out 
with a standardized $\mathrm{KOH}$ solution in a thermostatted extraction vessel kept at $25 \pm 0.1{ }^{\circ} \mathrm{C}$. The $\mathrm{pH}$ was measured continuously. The state of equilibrium was monitored on the basis of changes of the electromotive force. When the electromotive force after the titrant addition changed by less then $0.1 \mathrm{mV}$ in $3 \mathrm{~min}$, then the state was recognized as being stable.

\section{Results and Discussion}

Flufenamic acid is an ampholyte compound with one acidic and one basic functional group in its molecule. Depending on the $\mathrm{pH}$ of the aqueous solutions, this compound can exist as a protonated form $\mathrm{H}_{2} \mathrm{R}^{+}$, as a neutral form $\mathrm{HR}$ (as unionized $\mathrm{HR}^{0}$ or as a zwitterion $\mathrm{HR}^{ \pm}$, which are indistinguishable by acid-base titration), or as an anionic form $\mathrm{R}^{-}$(Fig. 1). Literature data relating to dissociation constants of the tested acid are both incomplete (refer only to $\mathrm{p} K_{\mathrm{a} 2}$ ) and divergent. These discrepancies are probably caused by difficulties in determining these constants because of its very low solubility in water. Depending on the methods and conditions, the following different values of $\mathrm{p} K_{\mathrm{a} 2}$ were obtained i.e.: 3.85 (value determined theoretically) [31], 3.97 (capillary electrophoresis) [32], 4.91 (capillary isotachophoretic) [33], 5.0 (spectrophotometric method) [34], 5.84 (potentiometric method in the acetone (5-10\%) + water system) [35], and 5.94 (potentiometric method in the ethanol $(50 \%)+$ water system) [36].

The dissociation constants $K_{\mathrm{a} 1}$ and $K_{\mathrm{a} 2}$ are expressed by Eqs. 5 and 6 [37]:

$$
\begin{aligned}
K_{\mathrm{a} 1} & =\frac{\left(\left[\mathrm{HR}^{ \pm}\right]+\left[\mathrm{HR}^{0}\right]\right)\left[\mathrm{H}^{+}\right]}{\left[\mathrm{H}_{2} \mathrm{R}^{+}\right]} \\
K_{\mathrm{a} 2} & =\frac{\left[\mathrm{R}^{-}\right]\left[\mathrm{H}^{+}\right]}{\left[\mathrm{HR}^{ \pm}\right]+\left[\mathrm{HR}^{0}\right]}
\end{aligned}
$$

The potentiometric method is recommended by many authors for determining the dissociation constants of amino acids. One of the barriers limiting the use of this method is having a too low solubility of the test compound in water, as in the case for flufenamic acid. To resolve this solubility problem in the present study, potentiometric titrations were performed in the MDM + water solvent system (containing 31.8-56.5 wt\% of MDM).

Analysis of the titration data was performed using Microsoft's Excel computer package with the help of the modified spreadsheet presented in [27], via curve fitting of the difference curve (degree of protonation versus $\mathrm{pH}$ ). The initial estimates of the $\mathrm{p}_{\mathrm{s}} K_{\mathrm{a}}$ values, which are

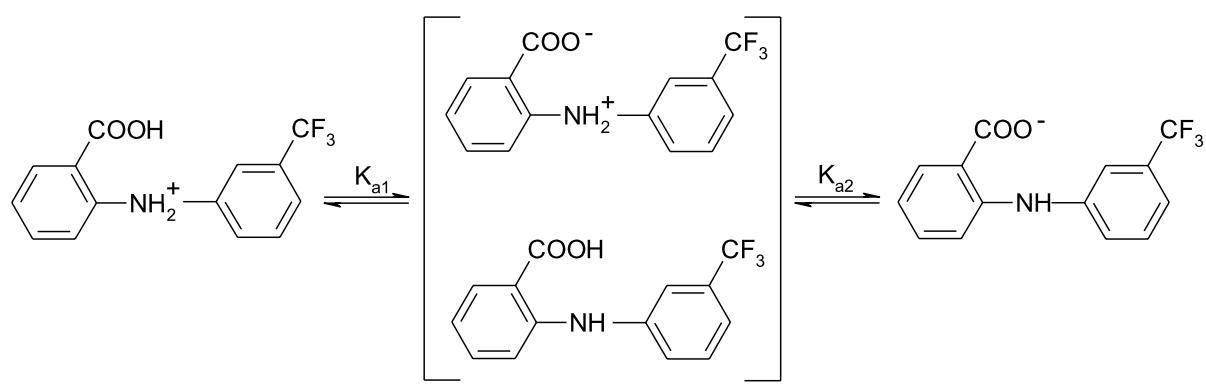

Fig. 1 Reaction scheme for flufenamic acid in aqueous solution 
the apparent ionization constants in the mixed solvent, were obtained from the difference Bjerrum plots using Eq. 7 [27, 38, 39]:

$$
n \mathrm{H}=\left\{[\mathrm{HCl}]-[\mathrm{KOH}]+n \mathrm{~L}-\left[\mathrm{H}^{+}\right]+\left(K_{\mathrm{w}} /\left[\mathrm{H}^{+}\right]\right)\right\} / \mathrm{L}
$$

where $n$ is the number of dissociable protons introduced into the solution by the substance $\mathrm{L}, \mathrm{L}$ is the total weak acid concentration, $[\mathrm{HCl}]$ and $[\mathrm{KOH}]$ are the concentrations of added strong acid and base, respectively, and $K_{\mathrm{w}}$ is the ionization constant of water in the MDM + water mixed solvent.

The obtained values were then refined by a weighted nonlinear least-squares procedure using the Solver program from Microsoft Excel, to find the best fit of the calculated curve to the theoretical function. Subsequently, to determine the best aqueous phase $\mathrm{p} K_{\mathrm{a} 1}$ and $\mathrm{p} K_{\mathrm{a} 2}$ values, the refined values of $\mathrm{p}_{\mathrm{s}} K_{\mathrm{a}}$ were extrapolated to zero co-solvent concentration by the Yasuda-Shedlovsky procedure expressed by Eq. 8 [17-19]:

$$
p_{\mathrm{s}} K_{\mathrm{a}}+\log _{10}\left[\mathrm{H}_{2} \mathrm{O}\right]=a / \varepsilon+b
$$

where $\left[\mathrm{H}_{2} \mathrm{O}\right]$ is the molar water concentration of the given solvent mixture, and $\varepsilon$ is the dielectric constant of the co-solvent mixture

The obtained values of $\mathrm{p}_{\mathrm{s}} K_{\mathrm{a}}$ for flufenamic acid are presented in Table 1.

Figure 2 shows the Yasuda-Shedlovsky plots of flufenamic acid in the MDM + water solvent system. The following linear relationships (Eqs. 9 and 10) were obtained by extrapolation to zero co-solvent concentration (for the dielectric constant of pure water $\left.\frac{100}{\varepsilon_{\mathrm{H}_{2} \mathrm{O}}}=\frac{100}{78.38}=1.28\right)$ :

$$
\begin{aligned}
& p_{\mathrm{s}} K_{\mathrm{a} 1}+\log _{10}\left[\mathrm{H}_{2} \mathrm{O}\right]=5.02-280.48 / \varepsilon \\
& p_{\mathrm{s}} K_{\mathrm{a} 2}+\log _{10}\left[\mathrm{H}_{2} \mathrm{O}\right]=4.48+167.60 / \varepsilon
\end{aligned}
$$

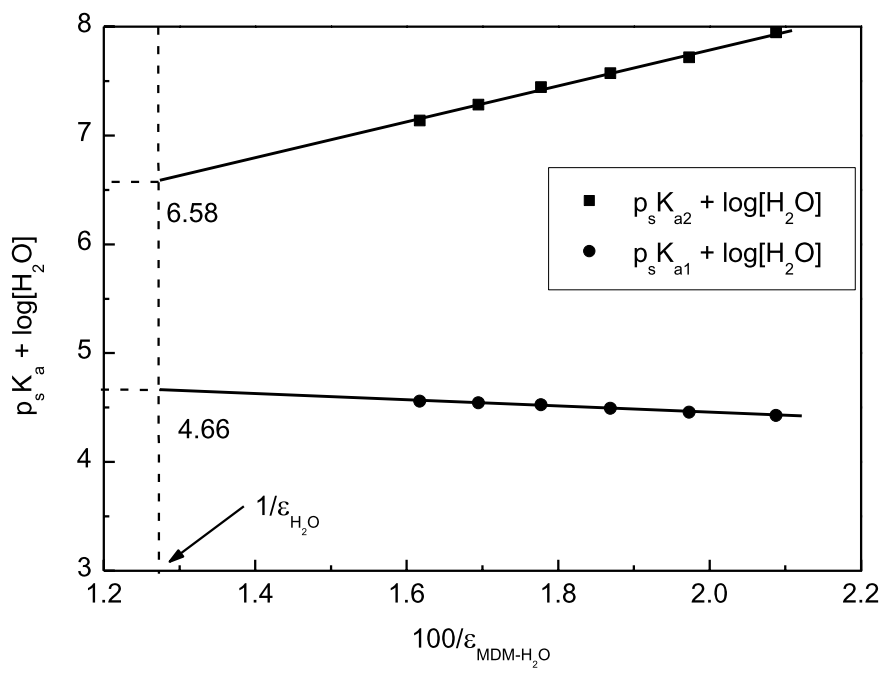

Fig. 2 Yasuda-Shedlovsky plot for flufenamic acid in MDM + water mixtures for determination of the p $K_{\mathrm{a} 1}$ and $\mathrm{p} K_{\mathrm{a} 2}$ values 
It should be noted that, as for most ampholytes, the slope of the Yasuda-Shedlovsky extrapolation function concerning a basic group is negative while the slope corresponding to an acidic group is positive $[24,26]$. The $\mathrm{p} K_{\mathrm{a} 1}$ and $\mathrm{p} K_{\mathrm{a} 2}$ values obtained by this method are $2.92 \pm 0.01$ and $4.84 \pm 0.04$, respectively. The isoelectric point $\mathrm{p} H_{\mathrm{i}}$ was identified at $\mathrm{pH}=3.88 \pm 0.03$.

Based upon the determined values of $K_{\mathrm{a} 1}$ and $K_{\mathrm{a} 2}$, the fractional concentrations of the species can be calculated using the following formulae [40]:

$$
\begin{gathered}
\alpha_{\mathrm{H}_{2} \mathrm{R}^{+}}=\frac{\left[\mathrm{H}^{+}\right]^{2}}{\left[\mathrm{H}^{+}\right]^{2}+K_{\mathrm{a} 1}\left[\mathrm{H}^{+}\right]+K_{\mathrm{a} 1} K_{\mathrm{a} 2}} \\
\alpha_{\mathrm{HR}}=\frac{K_{\mathrm{a} 1}\left[\mathrm{H}^{+}\right]}{\left[\mathrm{H}^{+}\right]^{2}+K_{\mathrm{a} 1}\left[\mathrm{H}^{+}\right]+K_{\mathrm{a} 1} K_{\mathrm{a} 2}} \\
\alpha_{\mathrm{R}^{-}}=\frac{K_{\mathrm{a} 1} K_{\mathrm{a} 2}}{\left[\mathrm{H}^{+}\right]^{2}+K_{\mathrm{a} 1}\left[\mathrm{H}^{+}\right]+K_{\mathrm{a} 1} K_{\mathrm{a} 2}}
\end{gathered}
$$

The corresponding distribution diagram of flufenamic acid is presented in Fig. 3.

It was found that the protonated form of the amino acid $\mathrm{H}_{2} \mathrm{R}^{+}$substantially predominates in the strongly acidic range $(\mathrm{pH}<3.0)$, while over the $\mathrm{pH}$ range 3.0-5.0 the main form is the neutral species $\mathrm{HR}\left([\mathrm{HR}]=\left[\mathrm{HR}^{0}\right]+\left[\mathrm{HR}^{ \pm}\right]\right)$, whereas the anionic form $\mathrm{R}^{-}$is dominant at $\mathrm{pH}>$ 5.0. At the physiological $\mathrm{pH}=7.4$, flufenamic acid exist mainly in the anionic form.

The partitioning profile $D=f(\mathrm{pH})$ of flufenamic acid in the toluene + water system was obtained by the classical shaking flask method and presented in Fig. 4. Values of the distribution ratio were calculated in accordance with Nernst's equation:

$$
D=\frac{c_{\mathrm{HR}, \mathrm{o}}}{c_{\mathrm{HR}, \mathrm{w}}}
$$

where $c_{\mathrm{HR}, \mathrm{o}}$ and $c_{\mathrm{HR}, \mathrm{w}}$ are the total concentration of amino acid in the organic and aqueous phases, respectively.

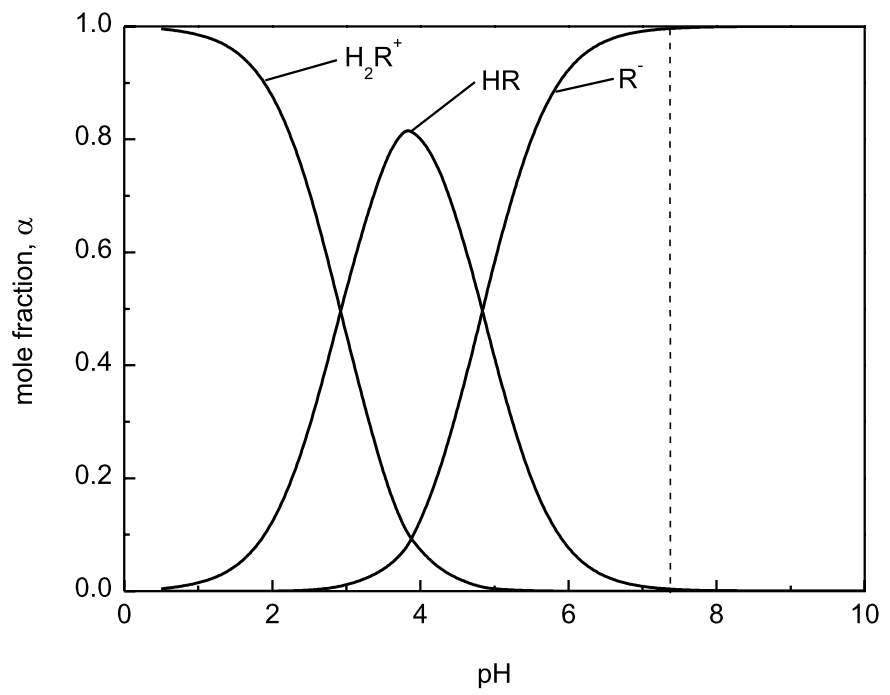

Fig. 3 The distribution diagram of flufenamic acid 


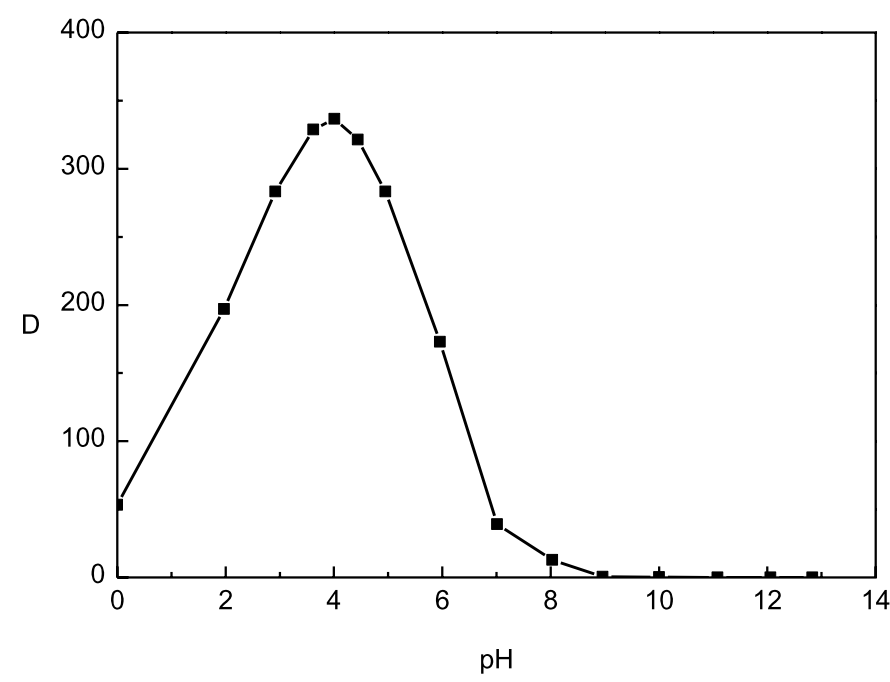

Fig. 4 The partitioning profile of flufenamic acid obtained by the shaking flask method in the toluene + water system

One can conclude that the partitioning profile has an approximately parabolic shape with a maximum around the isoelectric point. Moreover, the obtained results show that maximum extraction efficiency for flufenamic acid occurs in the $\mathrm{pH}=3.0-5.0$ range, and this $\mathrm{pH}$ range corresponds to the $\mathrm{pH}$ range where the neutral form of this acid $\mathrm{HR}$ is dominant. Application of spectroscopic measurements allows one to determine which form of the acid is extracted. Analyses of the UV-VIS spectra in the aqueous (at $\mathrm{pH}$ about 1, 4, and 8) and organic phases shows different spectra for the cationic, neutral and anionic forms in the aqueous phases, while identical spectra were obtained in the organic phases (toluene) at each $\mathrm{pH}$. Moreover, the spectra obtained in the organic phase are identical with the spectra of flufenamic acid in the corresponding pure solvent (identified as being that of the neutral form) for each investigated system. This method was recommended by Takács-Novák et al. [41] as giving very simple but exact experimental evidence for the partitioning of the neutral form, even when it is only a minor component. These findings show that it is not the ion pair but only the neutral form of the acid HR that is transferred from the aqueous to the organic phase. The same results were obtained for other compounds having similar structure (mefenamic and $N$-phenylanthranilic acid) [42,43], which confirms the validity of this method.

Taking into consideration the models of single and multistep equilibria, which were accurately described in [42-44], and the results of the potentiometric titrations in two-phase organic solvent-aqueous solutions, graphs of the dependences of $c_{\mathrm{HR}, \mathrm{o}} /[\mathrm{HR}]_{\mathrm{w}}$ on $[\mathrm{HR}]_{\mathrm{w}}$ for flufenamic acid in the two-phase systems organic solvent + aqueous solution, were prepared and are presented in Fig. 5. Because the obtained dependences are linear, determining the values of the distribution constants $K_{\mathrm{D}}$ and dimerization constants $K_{\mathrm{dim}}$ was possible by linear regression of Eq. 15:

$$
\frac{c_{\mathrm{HR}, \mathrm{o}}}{[\mathrm{HR}]_{\mathrm{w}}}=K_{\mathrm{D}}+2 K_{\mathrm{D}}^{2} K_{\mathrm{dim}}[\mathrm{HR}]_{\mathrm{w}}
$$

where $K_{\mathrm{D}}$ is the distribution constant for the neutral form of flufenamic acid $\left(K_{\mathrm{D}}=\right.$ $\left.[\mathrm{HR}]_{\mathrm{o}}[\mathrm{HR}]_{\mathrm{w}}^{-1}\right), K_{\mathrm{dim}}$ is the dimerization constant of the neutral form of flufenamic acid in 


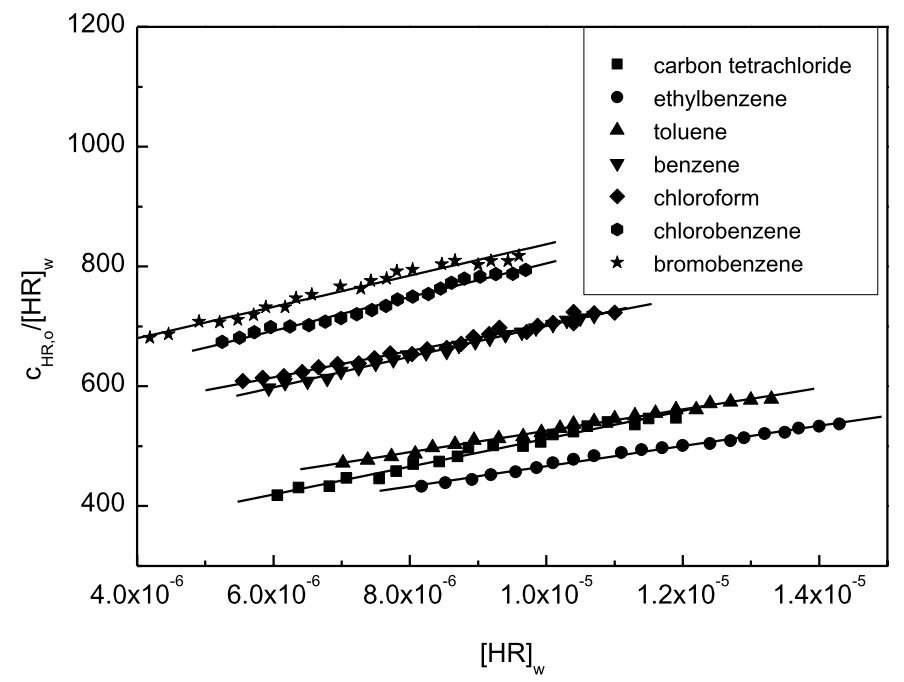

Fig. 5 Plot of $c_{\mathrm{HR}, \mathrm{o}} /[\mathrm{HR}]_{\mathrm{W}}$ versus $[\mathrm{HR}]_{\mathrm{W}}$ for flufenamic acid in two-phase systems: organic solvent (carbon tetrachloride, ethylbenzene, toluene, benzene, chloroform, chlorobenzene, or bromobenzene) + aqueous solution. The points denote the experimental data, while the solid lines have been determined by linear regression of Eq. 15 using the least-squares method

Table 2 Evaluated values of the distribution $\left(K_{\mathrm{D}}\right)$ and dimerization $\left(K_{\mathrm{dim}}\right)$ constants for flufenamic acid in the two-phase systems: organic solvent + aqueous solution and the obtained values of the correlation coefficient statistical criteria

\begin{tabular}{llllll}
\hline Solvent & $\begin{array}{l}\text { Hildebrand } \\
\text { solubility } \\
\text { parameter, } \\
\delta /\left(\mathrm{kJ}^{1 / 2} \cdot \mathrm{m}^{-3 / 2}\right.\end{array}$ & $\begin{array}{l}\text { Distribution } \\
\text { constant, } \\
K_{\mathrm{D}}\end{array}$ & $\begin{array}{l}\text { Dimerization } \\
\text { constant, } \\
K_{\text {dim }}\end{array}$ & $\begin{array}{l}\text { Correlation } \\
\text { coeffi- } \\
\text { cient, } R\end{array}$ & $\begin{array}{l}\text { Number of } \\
\text { experimental } \\
\text { points, } n\end{array}$ \\
\hline Carbon tetrachloride & 17.61 & $280 \pm 13$ & $144 \pm 4$ & 0.9896 & 23 \\
Ethylbenzene & 17.84 & $298 \pm 8$ & $95 \pm 2$ & 0.9961 & 21 \\
Toluene & 18.23 & $346 \pm 7$ & $75 \pm 3$ & 0.9972 & 22 \\
Benzene & 18.72 & $444 \pm 7$ & $65 \pm 2$ & 0.9980 & 24 \\
Chloroform & 19.05 & $482 \pm 12$ & $47 \pm 2$ & 0.9910 & 23 \\
Chlorobenzene & 19.44 & $518 \pm 11$ & $51 \pm 1$ & 0.9946 & 21 \\
Bromobenzene & 19.74 & $576 \pm 15$ & $39 \pm 1$ & 0.9860 & 22 \\
\hline
\end{tabular}

the organic phase $\left(K_{\mathrm{dim}}=\left[(\mathrm{HR})_{2}\right]_{\mathrm{o}}[\mathrm{HR}]_{\mathrm{O}}^{2-}\right),[\mathrm{HR}]_{\mathrm{w}}$ is the concentrations of the neutral form of flufenamic acid in the aqueous phase, and $c_{\mathrm{HR}, \mathrm{o}}$ the total concentrations of flufenamic acid in the organic phase $\left(c_{\mathrm{HR}, \mathrm{o}}=[\mathrm{HR}]_{\mathrm{o}}+2\left[(\mathrm{HR})_{2}\right]_{\mathrm{o}}\right)$.

The calculated values of $K_{\mathrm{D}}$ and $K_{\mathrm{dim}}$ are presented in Table 2 . The accuracy of the determination of these constants was assessed for the $95 \%$ confidence interval of the Student's test.

It has been found that the values of $K_{\mathrm{D}}$ and $K_{\mathrm{dim}}$ depend on the polarity of the organic solvent used. Moreover, the values of the distribution constants $K_{\mathrm{D}}$ increase while the values of the dimerization constants $K_{\text {dim }}$ decrease with increasing values of the Hildebrand solubility parameter $\delta$ of the organic solvent. The lowest value of $K_{\mathrm{D}}$ was observed in the 


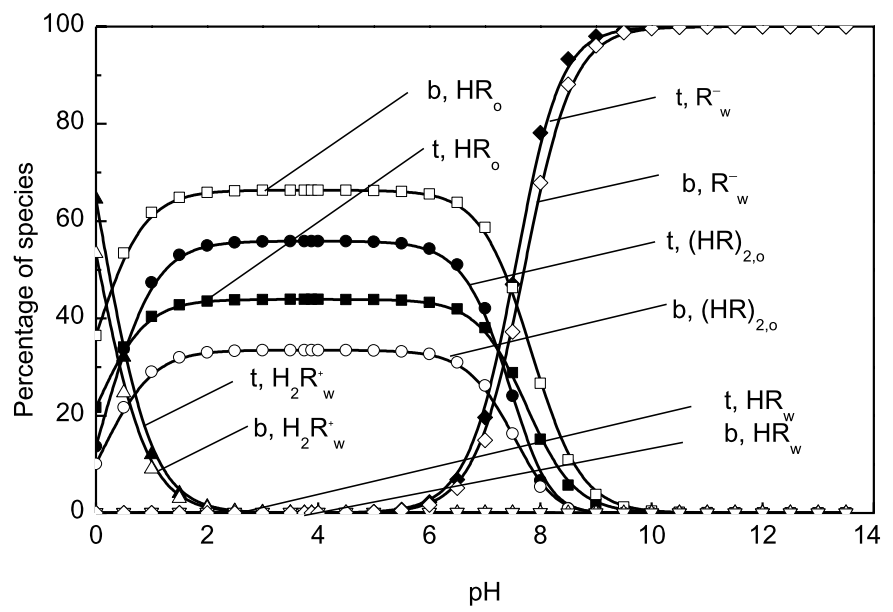

Fig. $6 \mathrm{pH}$ dependence of percentage of flufenamic acid species in two-phase systems: organic solvent ( $\mathrm{t}$ - carbon tetrachloride, $\mathrm{b}$ - bromobenzene $)+$ aqueous solution

system with carbon tetrachloride $\left(K_{\mathrm{D}}=280, \delta=17.61\right)$, while the highest was found in the system with bromobenzene $\left(K_{\mathrm{D}}=576, \delta=19.74\right)$. At the same time, the dimerization constant $K_{\text {dim }}$ decreases from 144 (carbon tetrachloride) to 39 (bromobenzene). In other words, an increase of the solvent polarity causes a decrease of the dimerization constant. In addition, flufenamic acid, when compared with mefenamic and niflumic acids, achieved significantly higher values of the distribution constant under similar conditions [42, 43]. It should be noted that value of distribution constant of flufenamic acid in the octan-1-ol + water system is considerably higher than in the systems described in this paper $\left(K_{\mathrm{D}}\right.$ is over three orders of magnitude higher) [9].

Based on the determined values of dissociation constants $K_{\mathrm{a} 1}$ and $K_{\mathrm{a} 2}$, distribution constants $K_{\mathrm{D}}$, dimerization constants $K_{\text {dim }}$, as well as the molar balance of amino acid in the studied systems, the content of the particular forms of flufenamic acid in both phases was calculated as a function of $\mathrm{pH}$ of the aqueous phase. The results obtained for the systems with extremely different $K_{\mathrm{D}}$ and $K_{\mathrm{dim}}$ values are presented in Fig. 6.

The obtained results show that flufenamic acid, in the $\mathrm{pH}$ range between 1 to 7 , occurs mainly in the organic phase as the monomeric $\mathrm{HR}_{\mathrm{o}}$ and dimeric $(\mathrm{HR})_{2, \mathrm{o}}$ forms. The percentage of acid in the monomeric form $\mathrm{HR}_{\mathrm{o}}$ in the organic phase is equal to about $66 \%$ for the system with bromobenzene, and about $44 \%$ for the system with carbon tetrachloride The percentage of acid in the dimeric form $(\mathrm{HR})_{2, \mathrm{o}}$ in those systems is equal about $34 \%$ for bromobenzene and about $56 \%$ for carbon tetrachloride. Under the same conditions, the percentage of the monomeric form of the acid in the aqueous phase $\mathrm{HR}_{\mathrm{w}}$ is very low, $0.12 \%$ for the system with bromobenzene and $0.16 \%$ for the system with carbon tetrachloride. Increasing the $\mathrm{pH}$ of the aqueous phase $(\mathrm{pH}>7)$ results in decreasing concentrations of the neutral forms $\mathrm{HR}_{\mathrm{o}}, \mathrm{HR}_{2, \mathrm{o}}, \mathrm{HR}_{\mathrm{w}}$, and a simultaneous increase of the concentration of the anionic form $\mathrm{R}_{\mathrm{w}}^{-}$. At higher $\mathrm{pH}$ values $(\mathrm{pH}>8.0)$ in both systems, flufenamic acid occurs only in the aqueous phase in the anionic form $\mathrm{R}_{\mathrm{w}}^{-}$. 


\section{Conclusions}

Due to the fact that flufenamic acid is widely applied in medicine, a detailed understanding of its equilibria in aqueous solution and two-phase systems is very important. For this reason, in this paper a detailed analysis of flufenamic acid was carried out and the fundamental physicochemical parameters such as dissociation, distribution and dimerization constants were determined. Titrations in the MDM + water system and application of the YasudaShedlovsky extrapolation method allowed the determination of the dissociation constants $\left(K_{\mathrm{a} 1}\right.$ and $\left.K_{\mathrm{a} 2}\right)$ and the isoelectric point in aqueous solution.

Application of the UV-VIS analysis permitted making of the partitioning profile of flufenamic acid in the toluene + water system. It has an approximately parabolic shape with a maximum near the isoelectric point. This behavior indicates that only the neutral form of the acid HR is transferred from the aqueous to organic phase. It has been shown that the potentiometric method is suitable for determining the distribution and dimerization constants. The obtained distribution constant values increase when the polarity of the organic solvents increase, while for the dimerization constant the opposite trend is observed. The physicochemical properties of flufenamic acid in the two-phase systems were described using the obtained values of $K_{\mathrm{D}}$ and $K_{\mathrm{dim}}$. It has also been demonstrated that the influence of the aqueous phase $\mathrm{pH}$ on the concentrations of the various forms of this acid is particularly evident in the $\mathrm{pH}$ range $0-8$. Moreover, the distribution of flufenamic acid in the two-phase systems practically proceeds in the same $\mathrm{pH}$ range.

Open Access This article is distributed under the terms of the Creative Commons Attribution Noncommercial License which permits any noncommercial use, distribution, and reproduction in any medium, provided the original author(s) and source are credited.

\section{References}

1. Davis, T.D., Morris, K.R., Huang, H., Peck, G.E., Stowell, J.G., Eisenhauer, B.J., Hilden, J.L., Gibson, D., Bym, S.R.: In situ monitoring of wet granulation using online X-ray powder diffraction. Pharm. Res. 20, 1851-1857 (2003)

2. Bettaieb, L., Aaron, J.-J.: Photochemically-induced fluorescence properties and determination of flufenamic acid, a non-steroidal anti-inflammatory drug, in urine and pharmaceutical preparation. Turk. J. Chem. 25, 165-171 (2001)

3. Abdel-Hamid, M.E., Novotny, L., Hamza, H.: Determination of diclofenac sodium, flufenamic acid, indomethacin and ketoprofen by LC-APCI-MS. J. Pharm. Biomed. Anal. 24, 587-594 (2001)

4. Lopez, C.H., Bracht, A., Yamamoto, N.S., Ishii-Iwamoto, E.L., Sampaio, E., Kelmer-Bracht, A.M.: The action of flufenamic acid and other nonsteroidal anti-inflammatories on sulfate transport in the isolated perfused rat liver. Gen. Pharmacol. 32, 713-720 (1999)

5. Papadoyannis, I.N., Zotou, A.C., Samanidou, V.F.: Simultaneous reversed-phase gradient-HPLC analysis of anthranilic acid derivatives in anti-inflammatory drugs and samples of biological interest. J. Liq. Chromatogr. 15, 1923-1945 (1992)

6. Gonzales, G., Ventura, R., Smith, A.K., Tore, R., Segura, J.: Detection of non-steroidal anti-inflammatory drugs in equine plasma and urine by gas chromatography-mass spectrometry. J. Chromatogr. A 719, 251-264 (1996)

7. Amor-García, I., Blanco-López, M.C., Lobo-Castañón, M.J., Miranda-Ordieres, A.J., Tuñón-Blanco, P.: Flufenamic acid determination in human serum by adsorptive voltammetry with in situ surfactant modified carbon paste electrodes. Electroanalysis 17, 1555-1562 (2005)

8. Sabry, S.M., Mahgoub, H.: Voltammetric, spectrofluorimetric and spectrophotometric methods to determine flufenamic acid. J. Pharm. Biomed. Anal. 21, 993-1001 (1999)

9. Scherrer, R.A., Donovan, S.F.: Automated potentiometric titrations in $\mathrm{KCl} /$ water-saturated octanol: method for quantifying factors influencing ion-pair partitioning. Anal. Chem. 81, 2768-2778 (2009)

10. Machatha, S.G., Yalkowsky, S.H.: Comparison of the octanol/water partition coefficients calculated by ClogP, ACDlogP and KowWin to experimentally determined values. Int. J. Pharm. 294, 185-192 (2005) 
11. Perlovich, G.L., Surov, A.O., Bauer-Brandl, A.: Thermodynamic properties of flufenamic and niflumic acids-specific and non-specific interactions in solution and in crystal lattices, mechanism of solvation, partitioning and distribution. J. Pharm. Biomed. Anal. 45, 679-687 (2007)

12. Meloun, M., Havel, J., Högfeld, E.: Computation of solution equilibria: A guide to methods in potentiometry, extraction, and spectrophotometry. Ellis Horwood Ltd., Chichester (1988)

13. Wróbel, R., Chmurzyński, L.: Potentiometric $\mathrm{p} K_{\mathrm{a}}$ determination of standard substances in binary solvent systems. Anal. Chim. Acta 405, 303-308 (2000)

14. Martell, A.B., Motekaitis, R.J.: Determination and Use of Stability Constants, 2nd edn. VCH, New York (1992)

15. Barbosa, J., Barron, D., Beltrán, J.L., Sanz-Nebot, V.: PKPOT, a program for the potentiometric study of ionic equilibria in aqueous and non-aqueous media. Anal. Chim. Acta 317, 75-81 (1995)

16. Gans, P., Sabatini, A., Vacca, A.: Investigation of equilibria in solution. Determination of equilibrium constants with the HYPERQUAD suite of programs. Talanta 43, 1739-1753 (1996)

17. Takács-Novák, K., Avdeef, A., Box, K.J., Podányi, B., Szász, G.: Determination of protonation macroand microconstants and octanol/water partition coefficient of the antiinflammatory drug niflumic acid. J. Pharm. Biomed. Anal. 12, 1369-1377 (1994)

18. Fallavena, P.R., Schapoval, E.E.: $\mathrm{p} K_{\mathrm{a}}$ determination of nimesulide in methanol-water mixtures by potentiometric titrations. Int. J. Pharm. 158, 109-112 (1997)

19. Avdeef, A., Box, K.J., Comer, J.E.A., Hadley, M., Hibbert, C.: pH-metric $\log P$ 11. $\mathrm{p} K_{\mathrm{a}}$ determination of water-insoluble drugs in organic solvent-water mixtures. J. Pharm. Biomed. Anal. 20, 631-641 (1999)

20. Takács-Novák, K., Box, K.J., Avdeef, A.: Potentiometric $\mathrm{p} K_{\mathrm{a}}$ determination of water-insoluble compounds. Validation study in methanol/water mixtures. Int. J. Pharm. 151, 235-248 (1997)

21. Avdeef, A., Comer, J.E.A., Thomson, J.S.: pH-Metric logP.3. Glass electrode calibration in methanolwater, applied to $\mathrm{p} K_{\mathrm{a}}$ determination of water-insoluble substances. Anal. Chem. 65, 42-49 (1993)

22. Bacarella, A.L., Grunwald, E., Marshall, H.P., Purlee, E.L.: The potentiometric measurement of acid dissociation constants and $\mathrm{pH}$ in the system methanol-water. $\mathrm{p} K_{\mathrm{a}}$ values for carboxylic acids and anilinium ions. J. Org. Chem. 20, 747-742 (1955)

23. Ràfols, C., Rosés, M., Bosch, E.: Dissociation constants of several non-steroidal anti-inflammatory drugs in isopropyl alcohol/water mixtures. Anal. Chim. Acta 350, 249-255 (1997)

24. Völgyi, G., Ruiz, R., Box, K., Comer, J., Bosch, E., Takács-Novák, K.: Potentiometric and spectrophotometric $\mathrm{p} K_{\mathrm{a}}$ determination of water-insoluble compounds: validation study in a new cosolvent system. Anal. Chim. Acta 583, 418-428 (2007)

25. Erdemgil, F.Z., Şanli, S., Şanli, N., Özkan, G., Barbosa, J., Guiteras, J., Beltrán, J.L.: Determination of $\mathrm{p} K_{\mathrm{a}}$ values of some hydroxylated benzoic acids in methanol-water binary mixtures by LC methodology and potentiometry. Talanta 72, 489-496 (2007)

26. Box, K.J., Völgyi, G., Ruiz, R., Comer, J.E., Takács-Novák, K., Bosch, E., Ràfols, C., Rosés, M.: Physicochemical properties of a new multicomponent cosolvent system for the $\mathrm{p} K_{\mathrm{a}}$ determination of poorly soluble pharmaceutical compounds. Helv. Chim. Acta 90, 1538-1553 (2007)

27. Barzanti, C., Evans, R., Fouquet, J., Gouzin, L., Howarth, N.M., Kean, G., Levet, E., Wang, D., Wayemberg, E., Yeboah, A.A., Kraft, A.: Potentiometric determination of octanol-water and liposome-water partition coefficients $(\log P$ ) of ionizable organic compounds. Tetrahedron Lett. 48, 3337-3341 (2007)

28. Billo, E.J.: Excel for Chemists: A Comprehensive Guide, 2nd edn. Wiley-VCH, New York (2001)

29. Bates, R.G., Guggenheim, E.A.: Report on the standardization of $\mathrm{pH}$ and related terminology. Pure Appl. Chem. 1, 163-168 (1960)

30. Atkins, P.: Physical Chemistry. Oxford University Press, Oxford (1998)

31. Terada, H., Muraoka, S., Fujita, T.: Structure activity relations. 7. Structure-activity relations of fenamic acids. J. Med. Chem. 17, 330-334 (1974)

32. Shalaeva, M., Kenseth, J., Lombardo, F., Bastin, A.: Measurement of dissociation constants (p $K_{\mathrm{a}}$ values) of organic compounds by multiplexed capillary electrophoresis using aqueous and cosolvent buffers. J. Pharm. Sci. 97, 2581-2606 (2008)

33. Polášek, M., Pospíšilová, M., Urbánek, M.: Capillary isotachophoretic determination of flufenamic, mefenamic, niflumic and tolfenamic acid in pharmaceuticals. J. Pharm. Biomed. Anal. 23, 135-142 (2000)

34. Herzfeldt, C.D., Kümmel, R.: Dissociation constants, solubilities and dissolution rates of some selected nonsteroidal antiinflammatories. Drug Dev. Ind. Pharm. 9, 767-793 (1983)

35. Saeki, K., Muraoka, S., Yamasaki, H.: Anti-inflammatory properties of $N$-phenylanthranilic acid derivatives in relation to uncoupling of oxidative phosphorylation. Jpn. J. Pharmacol. 22, 187-199 (1972)

36. Brittain, H.G., Prankerd, R.J.: Profiles of Drug Substances, Excipients and Related Methodology. Elsevier Academic, Amsterdam (2007)

37. Langlois, M.-H., Montagut, M., Dubost, J.-P., Grellet, J., Saux, M.-C.: Protonation equilibrium and lipophilicity of moxifloxacin. J. Pharm. Biomed. Anal. 37, 389-393 (2005) 
38. Avdeef, A.: pH-metric logP.1. Difference plots for determining ion-pair octanol-water partition coefficients of multiprotic substances. Quant. Struct.-Act. Relatsh. 11, 510-517 (1992)

39. Degim, T., Zaimoglu, V., Akay, C., Degim, Z.: pH-Metric $\log K$ calculations of famotidine, naproxen, nizatidine, ranitidine and salicylic acid. Il Farmaco 56, 659-663 (2001)

40. Popović, G., Milovanivić, L., Kapetanović, V.: Study of acid-base equilibria of fleroxacin. J. Pharm. Biomed. Anal. 18, 859-863 (1998)

41. Takács-Novák, K., Józan, M., Szász, G.: Lipophilicity of amphoteric molecules expressed by the true partition coefficient. Int. J. Pharm. 113, 47-55 (1995)

42. Zapała, L., Kalembkiewicz, J.: Studies on the distribution of $N$-phenylanthranilic acid in two-phase system: aromatic solvent-water. Talanta 69, 601-607 (2006)

43. Zapała, L., Kalembkiewicz, J., Szlachta, J.: Studies on distribution of mefenamic acid in two-phase aromatic solvent-water systems. Pol. J. Chem. 79, 1235-1244 (2005)

44. Zapała, L., Kalembkiewicz, J., Sitarz-Palczak, E.: Studies on equilibrium of antyhranilic acid in aqueous solutions and in two-phase systems: aromatic solvent-water. Biophys. Chem. 140, 91-98 (2009) 